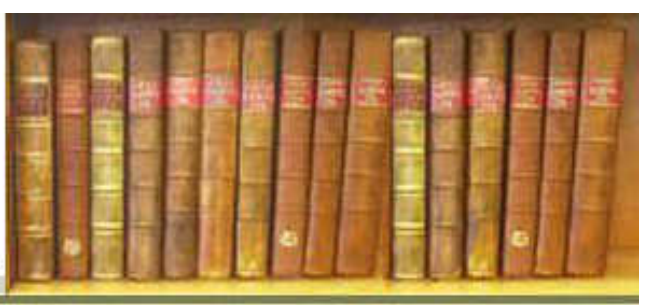

THE STATUS OF STRATEGIC PLANNING IN SMALL AND MEDIUM ENTERPRISES: PRIORITY OR AFTERTHOUGHT?

\title{
Corrinne Thompson
}

Dept of Business Management

University of Johannesburg

\section{Maria Bounds}

Dept of Business Management

University of Johannesburg

Geoff A. Goldman *

Dept of Business Management

University of Johannesburg

D-Ring 530, Kingsway Campus

PO Box 524

Auckland Park

2006

(011) 559-3172 (W)

(011) 559-2827 (F)

ggoldman@uj.ac.za

* To whom correspondence should be addressed 


\title{
THE STATUS OF STRATEGIC PLANNING IN SMALL AND MEDIUM ENTERPRISES: PRIORITY OR AFTERTHOUGHT?
}

\begin{abstract}
Small and medium enterprises (SMEs) are faced will many challenges, and the development of a sound strategy for the SME could define how these challenges are met which, in turn, could mean the difference between success or failure of the enterprise. If a sound strategy is major contributing factor to the success of a small business, but the evidence of sound strategic management (as taught in universities and business schools) is not present in successful SME's, one could question the way strategic management is conceptualised. The study thus aims to gather a greater understanding of strategic management - and strategy formulation practices in particular - within SME's. The study employed a qualitative, descriptive design with semi-structured interviews conducted with $12 \mathrm{SME}$ owners in Gauteng. Findings reveal that the majority of participants were in favour of and supported the notion of having a strategy for small and medium enterprises, but none of them made reference to a formal process regarding strategy formation.
\end{abstract}

Key words: Strategy; strategy formulation, small and medium businesses; planning; qualitative research.

\section{INTRODUCTION}

Small and medium enterprises are the end result of the entrepreneurial endeavour. O'Regan and Ghobadian, (2004b) depict small and medium enterprises (SME's) as the "bloodline of modern complex economies", as the establishment and longevity of SME's are a sign of a healthy and expanding economy. In order to preserve the competitive position of SME's, they are constantly challenged to optimally utilise the resources apportioned to innovative endeavours (Bennett \& Robson, 2003). This results in SME's requiring increased specialist knowledge which results in the need for external advice in the form of, inter alia, business consultation.

Protecting the competitive position of SME also requires attention to business strategy and the management of strategy within the SME. Strategic management is thus not the exclusive realm of corporate enterprises. In fact, SME's face many of the same challenges encountered by their larger, corporate counterparts (O'Regan \& Ghobadian, 2004a). Meers and Robertson (2007) similarly affirm that firms of all sizes are constantly challenged due to a multitude of factors such as globalisation, technology, emerging new markets and deregulation; and thus pro-activity (in the form of sound strategy) is needed to face these challenges. Strategy is thus no longer considered a luxury or optional; it is now a necessity.

Rapid economic and technological changes in the global marketplace have resulted in SME's exhibiting many of the management development needs traditionally reserved for corporate enterprises. In this regard, Mughan, Lloyd-Reason and Zimmerman (2004) state that insufficient research evidence exists on the significance, value and process of strategy and strategic management for SME's. Meers and Robertson (2007) purport that there is currently no evidence pointing towards an effective method for SME's when engaging in the process of strategy. Kraus, Harms and Schwarz (2006) reviewed a total of 24 empirical studies dealing with strategic management issues in SME's; and concluded that research into of strategic management efforts within SME's is still in its infancy. Similarly, Griggs (2002) conveys concern pertaining to the depth of previous research related to SME's and strategy; and further argues that such research used one-dimensional measures, which is not in line with the multi-dimensional nature of strategic management. 


\section{PURPOSE OF THE STUDY}

The dynamic nature of the business environment therefore necessitates organisations albeit SME's or corporate enterprises - to be more strategic in their everyday approach to business. Indeed, strategic management efforts have been linked to performance in SME's in several dimensions, according to Meers and Robertson (2007). However, within the realm of SME's, this necessity seems to be downplayed due to, amongst others, the scope of SME's, availability of resources and a diversion of energy to day-to-day operational issues. Unlike corporate enterprises, where the performance of the enterprise is dependent on a management team, SME's are (almost exclusively) dependent on the skills of the owner (Dyer \& Ross, 2008), who does not necessarily possess requisite knowledge or skills associated with managing an enterprise effectively and efficiently, which is a contributing factor to the failure of SME's.

However, not all SME's fail; many are quite successful. If sound strategy and the management thereof is a large contributing factor to the success of any business, but contemporary strategic management practices are not evident in SME's (even successful ones), then perhaps the issue is one of how strategic management is conceptualised. Consequently, the study endeavours to shed light on the following research question:

\section{Are there alternative views on the formulation and execution of strategy forthcoming from SME's?}

Seen against the backdrop of scant (and often superficial) research conducted on this issue, this study aims:

To gather a greater understanding of strategic management - and strategy formulation practices in particular - within SME's.

More specifically, this study intends to establish if SME's:

- conduct any strategy formulation exercises at all, and

- whether these practices follow conventions purported in contemporary academic literature within the realm of strategic management.

\section{AN OVERVIEW OF RELEVANT LITERATURE}

\section{Strategic management and strategy formulation}

The concept of strategic planning is often confused with strategy formulation. The distinction lies therein that strategy formulation has a strong entrepreneurial character, as managers have to choose between various strategic options; which implies an element of exploration, innovative thinking, creativity and risk-taking (Thompson, Strickland \& Gamble, 2005). The strategy formulation process is dependent on various internal factors, including employee participation, the culture of the organisation, the maturity of the businesses leadership and ultimately the linkage between strategy formulation and implementation (Pun, 2004).

Pun (2004) identifies the strategy formulation process as one in which an action plan is created together with the required procedures needed to put the plan into action. The purpose of the plan is to enable the consistency and credibility of the strategic choices made. The procedures, furthermore, facilitate functional strategies, which need to be put into place by functional managers in the organisation. The success of strategy formulation, (Feurer \& Chaharbaghi, 1997) depends on it being handled as part of individual responsibility throughout the organisation and not simply as a central function. This will considerably enhance the quality of knowledge used for strategy formulation and simultaneously lessen the timeframe and latent conflict associated with the acts of strategy implementation. 


\section{Strategy and performance linkages}

Strategic planning has been directly linked to organisational performance in small enterprises, according to Meers and Robertson (2007). Moreover, strategic planning is positively linked with improved performance across industries. Proper planning can result in improved profitability. However, before further exploring the linkages between strategy and performance, the controversy of the operational definition of 'performance' needs to be contemplated. Gibson and Cassar (2005) identify this as a point of confusion and dissemination of previous research. Performance is an indicator of growth in employment and sales income. The meaning of performance, according to Keats and Bracker (1998), may have a varying set of meanings for SMEs; this subsequently implies that it would be improper to apply the definition simultaneously to SMEs and large organisations..

Planning and performance linkages have also been established through studies of small organisations in the early stages of the organisation (Meers \& Robertson, 2007). Controversially, the findings of French, Kelly and Harrisons' (2004) research indicated that although there is a link between planning and performance, the link is not particularly strong. Furthermore, their research outcomes question the value of classical strategic planning for SMEs. Support of this is found in Perry's (2001) findings, which explain the lack of planning strength as being that formal planning is scarcely ever done by organisations with less than five employees. Perry (2001) proclaims that this may be due to such organisations not being required to develop a business plan to establish commercial credit or to borrow money.

SME owners personalise their strategies to react to the enterprises' performance, according to Van Gelderen, Frese and Thurik, (2000). When performing poorly, they pursue a reactive strategy, compared with high performing SMEs, whose owners start by focusing on the critical issues, followed by a more complete planning approach.

Review of the link between planning and performance (Kraus, et al., 2006), reveals that despite various studies, there are many inconsistencies in the findings of previous research. They explore possible reasons, including the differing definitions of strategic planning and that the analyses focused on varying aspects of strategic planning. Despite the findings of their literature review, the conclusion provided in the research undertaken by Kraus, et al. (2006) was that a higher degree of formalisation is associated with a higher degree of performance. They advise, accordingly, that it follows that SMEs might therefore, want to plan more formally than before.

\section{Formulation of strategy}

Strategy formulation is described by Grant Jackson in Corporate Finance and Strategy (Jackson, n.d.) as "the process of igniting, capturing and conveying strategic ideas". Strategy formulation should give clarity to what products or services the enterprise will deliver, what market they will enter, what capabilities are required and how the resources will be allocated to do so". Strategy formulation, and strategic management per se, It is not just applicable to corporate enterprises, SME's can, and do, benefit from the process of strategy formulation (Mintzberg, Ahlstrand \& Lampel, 1998). Ten schools of strategy formation are identified by Mintzberg et al (1998). These are described in Table 1.

Table 1: Ten schools of strategy formulation

\begin{tabular}{|l|l|}
\hline The design school & Strategy formation as a process of conception \\
\hline The planning school & Strategy formation as a formal process \\
\hline The positioning school & Strategy formation as an analytical process \\
\hline The entrepreneurial school & Strategy formation as a visionary process \\
\hline The cognitive school & Strategy formation as a mental process \\
\hline The learning school & Strategy formation as an emergent process \\
\hline
\end{tabular}




\begin{tabular}{|l|l|}
\hline The power school & Strategy formation as a process of negotiation \\
\hline The cultural school & Strategy formation as a collective process \\
\hline The environmental school & Strategy formation as a reactive process \\
\hline The configuration school & Strategy formation as a process of transformation. \\
\hline
\end{tabular}

Source: Mintzberg et al (1998:5)

As can be seen from Table1, thinking has evolved concerning how strategy formulation occurs and what the end purpose of the formed strategy should be. Some see strategy formulation as something that is the domain of top managers only, that it is embarked upon to satisfy business orientated objective only. On the other hand, some see strategy formulation as something all inclusive, that it has a role to play in transforming the organisation into something better and more sustainable in the long run.

\section{The significance of strategy to the small and medium enterprise}

It is quite evident that strategy and the management therof is of paramount importance to a business, irrespective of its' size or scope (Sandberg, Robinson \& Pearce, 2001). Questions such as "If your business were to shut down, to whom would it matter and why?" and "Which of your customers would miss you the most and why?" are not only relevant to large corporate, and multi-national enterprises, smaller owner-lead enterprises also need to engage with these issues (Montgomery, 2008).

Insufficient research-based evidence exists pertaining to the significance of strategic planning for SMEs (Mughan, Lloyd-Reason \& Zimmerman, 2004). Many SME's question the value of a strategic plan, falling back on the notion that entrepreneurs are pioneers of ideas and concepts (Sandberg, et al., 2001). These business owners focus on the daily running of the business, not the development of intricate, time consuming strategic plans. Sandberg, et al. (2001) report that at least half of all SMEs studied have no identifiable strategy.

SMEs seem less likely to pursue formal and rigid strategic planning. This could be due to limited resources, such as time and access to competitive intelligence, or simply due to the need to focus on operational contingencies. Dibrell, Crown and Bull, (2007) caution that managers who follow a structured planning process strictly, may become disconnected from the daily operations of the enterprise - something that can be ill afforded by the SME.

Research by Frese, Van Gelderen and Ombach (2000) examined the characteristics of SME's pertaining to their approach to strategy formulation. Although they assert that these SME owners do follow something tantamount to strategy, these are not consistently "rational or explicit". The outcome of Frese, et al's (2000) research established that the process characteristics of strategies for SMEs are related to their success, as these are a direct result of the actions of the owner/manager. More significantly, those owners who concentrate on the most important or difficult component of the business, will perform better than those who do not.

\section{Strategic planning for SMEs}

Planning in SMEs, according to Gibson and Cassar (2002), is mostly adaptive, short-term and focused on managing and positively exploiting scarce resources. Yusuf and Saffu (2005) found that SMEs typically embark on planning as a reactive response to specific events in their operating environment. Research undertaken by Stonehouse and Pemberton (2002), research indicate that a mere eight percent of the tested enterprises have never undertaken any form of planning exercise. According to Berman, Gordon and Sussman (1997), most SMEs lack any notion of proper business planning. They further purport that entrepreneurs are formally classified as small or even micro enterprises in the start-up phase 
of their business and would typically pay serious attention to proper business and strategic planning initiatives once it becomes evident that the enterprise needs to expand to ensure longevity. Further exploration pertaining to the relationship between planning and performance in SMEs is refined by Wijewardena, Zoysa, Fonseka and Perera (2004) insofar as the specific sophistication levels of such planning are concerned. Their research demonstrated that higher degrees of planning and control sophistication has direct lineage to improved sales performance in SMEs.

It can be seen from the preceding discussion that strategic planning and the formulation of strategy is of paramount importance, irrespective of the size of the enterprise. Proper and effective strategic management is a major contributing factor to the success of enterprises of all sizes. Yet, as far as SME's are concerned, there seems to be a glaring lack of conventional strategic management activities, even amongst those SME's that are successful in the long run. 'Conventional strategic management' refers to how we have been taught, in business schools and universities, to think about the element of business strategy and the strategic management process in totality. Literature suggests that SME's do not necessarily follow these conventions.

\section{RESEARCH DESIGN AND METHODOLOGY EMPLOYED IN THE STUDY}

\section{Research approach}

The study employed an interpretive research approach utilising qualitative methods. Walliman (2006) explains that interpretive research is based on the view that a person can only experience the world through his or her perceptions, which are influenced by preconceived ideas and beliefs. When interpretive research is embarked upon, one does not view the world externally, but from within the situation that is being studied (Walliman, 2006). This research approach thus attempts to understand the phenomena being studied through the meaning and interpretations that individuals assign to them.

Qualitative research methods were employed in this study to underpin the interpretive research approach. Strauss and Corbin (1998) define qualitative research as "any kind of research that produces findings not arrived at by means of statistical procedures or other means of quantification"; thus qualitative methods were decided upon as they assisted in uncovering a deeper level of understanding of strategy formulation (or equivalent) practices in SME's.

The study is also descriptive in nature, as is aims to understand how strategy formulation (or equivalent) endeavours unfold in SME's. As such, the experiences, perceptions, understandings and interpretations of SME owner/managers are crucial in attempting to reach the desired level of understanding.

\section{Research strategy}

This study was conducted as an ethnographic study. Babbie and Mouton (2004) describe an ethnographic study as producing findings derived from collecting data on the behaviour of (and in) a particular society. In this instance, SME owner/managers possess their own, unique identity which provides the opportunity to view the formulation of strategy from a different perspective. 


\section{Research setting}

This study was conducted amongst owner/managers of SME's across the Gauteng region. A major challenge was the fact that many of the owner/managers do not have formal business or management education, and therefore have their own (and often biased) views of what business strategy and strategy formulation are all about. This does not necessarily correspond with what contemporary literature purports on the issue.

\section{Entry and establishing the role of the researcher}

One of the researchers employed her personal network to gain access to SME owner/ managers. This researcher serves on the Sustainability Forum of her employer and as such, is in contact with and has access to SME owner/managers in various sectors. Potential research participants were identified by the researcher and approached individually to solicit their participation. None of these potential research participants declined to participate in the study.

\section{Sampling}

The sample for this study was selected using judgemental, non-probability sampling. Neuman (2000:196) suggests that when selecting research participants for qualitative studies, relevance to the research topic is more important than representativeness. Furthermore, it is exceedingly difficult to determine an optimal sample size for qualitative studies (Terre Blanche, Durheim \& Painter, 2006). As SME owner/managers represent diversity in terms of scope of business, sector and years of experience, it was decided to select critical cases (Flick, 2006) that would take cognisance of this heterogeneity. The decision was made to interview 12 SME owner/managers as 12 critical cases pertinent to this study

In determining these critical cases, it was decided that the sample would be based on SME's based in Gauteng. Furthermore, and importantly, the research sample comprises only SME's with which the researcher already had contact. Therefore, a degree of trust had already been established between the researcher and research participant, providing an appropriate platform for soliciting in depth data from research participants.

\section{Data collection}

Data was collected through the use of semi-structured interviews. Interviews provide an avenue for generating data by talking to people about how they go about their day-by day dealings (Miller and Brewer, 2003). The researcher's main function in an interview is to provide a framework for participants to express their views (Miller and Brewer, 2003).

For this study, the following topics, emergent from literature, were employed to guide the interviews:

- $\quad$ The need for strategy in SMEs.

- $\quad$ Strategy formation role-players in the SME.

- $\quad$ Planning and forecasting by SMEs.

- $\quad$ Competitive intelligence of SMEs.

- $\quad$ The SME strategy formation process.

- $\quad$ The link between strategy and SME performance.

Interviews were conducted personally by the researcher and lasted one hour on average. Transcription of the interviews (also done by the researcher) followed directly after each interview with notes and memo's (taken during interviews) incorporated into the transcripts. 
Interviews were conducted according to an interview guide were the researcher discussed a range of themes relevant to the study with participants. All interviews were recorded onto a voice recorder for the aim of transcription and future referrals.

\section{Recording of data}

Data were recorded onto a dictaphone. This allowed source data to be saved on Dictaphone cassette tapes. The researcher also took notes of non-verbal cues during interviews. As mentioned, these notes were incorporated into the transcripts to compliment the data recorded to the dictaphone.

\section{Data analysis}

The study employed thematic analysis. Braun and Clark (2006) purport that thematic analysis is a search for themes or patterns across a data set, rather than within a data item (such as, eg. an individual interview). Table 3.4 outlines the phases of thematic analysis, according to Braun and Clark (2006).

Table 2: Phases of thematic analysis

\begin{tabular}{|r|l|l|}
\hline & Phase & Description of the process \\
\hline 2 & $\begin{array}{l}\text { Familiarising yourself } \\
\text { with your data }\end{array}$ & $\begin{array}{l}\text { Transcribing data, reading and re-reading the data, noting down initial } \\
\text { ideas. }\end{array}$ \\
\hline 3 & Searching for themes & $\begin{array}{l}\text { Collating codes into potential themes, gathering all data relevant to each } \\
\text { potential theme. }\end{array}$ \\
\hline 4 & Reviewing themes & $\begin{array}{l}\text { Checking if the themes work in relation to the coded extracts (Level 1) } \\
\text { and the entire data set (Level 2), generating a thematic 'map' of the } \\
\text { analysis. }\end{array}$ \\
\hline 5 & $\begin{array}{l}\text { Defining and naming } \\
\text { themes }\end{array}$ & $\begin{array}{l}\text { On-going analysis to refine the specifics of each theme and the overall } \\
\text { story the analysis tells, generating clear definitions and names for each } \\
\text { theme. }\end{array}$ \\
\hline 6 & Producing the report & $\begin{array}{l}\text { The final opportunity for analysis. Selection of vivid, compelling extract } \\
\text { examples, final analysis of selected extracts, relating back of the } \\
\text { analysis to the research question and literature, producing a scholarly } \\
\text { report of the analysis. }\end{array}$ \\
\hline
\end{tabular}

\section{Strategies employed to ensure quality data}

For qualitative research to be deemed of good quality, trustworthiness needs to be considered in terms of four criteria (Lincoln \& Guba, 1985):

- Credibility: This study solicited data from a range of SME owner/managers. Observation was persistent, as the researcher was involved in recording the interviews, taking notes and memos, transcribing the data and eventually analysing the data. Furthermore, all interviews were preserved on Dictaphone cassette CD to ensure referential adequacy of the data.

- Transferability: In this study the idea was never to illuminate further than the context of SME's, so transferability here pertains to how the findings can be extrapolated to other SME's. In this case findings can be extrapolated to SME's in other regions as the critical cases included in this study take cognisance of the heterogeneity of SME's.

- Dependability: Assurance must be sought that applying the research to the same/similar research subjects in the same/similar contexts will produce similar results. Thus, if credibility is ensured, dependability is also ensured. 
- Confirmability: Cassette back-ups of raw data and notebooks (containing field notes) leave an adequate trail of how conclusions, interpretations and recommendations can be traced to their source.

Furthermore, all individuals who participated in the study did so on a voluntary basis and no coercion of participants took place. Participants were aware of the procedures followed during interviews, and gave their consent to participate with the knowledge that they could opt out of an interview at any stage if they felt uncomfortable. Research participants were assured of their anonymity and all information provided in the interviews was treated confidentially.

\section{Reporting}

As this study produced a myriad of findings, this article aims to provide a deeper understanding of how strategy formulation (or equivalent) efforts are embarked upon by SMEs. Findings are structured according to main themes emergent from the interview process. Excerpts from the interviews conducted were used to provide rich descriptions of the perceptions of the participants involved in this study.

\section{PRESENTATION AND DISCUSSION OF FINDINGS}

The nature of the critical cases selected for this sample is reflected in Table 3. As can be seen, all the SMEs are established and represent a wide range of products and services offered. These SME's employ between 2 and 52 staff members and realise an annual turnover of between R1.4 million and R32 million.

Table 3: Critical cases included in the study

\begin{tabular}{|l|l|l|}
\hline $\begin{array}{l}\text { SME } \\
\text { number }\end{array}$ & Years in existence & Focus of the business (products/services offered) \\
\hline 1 & 3 & Contract cleaning in the healthcare industry \\
\hline 2 & 6 & BBBEE consulting \\
\hline 3 & 8 & Linen provider to the healthcare industry \\
\hline 4 & 20 & IT consulting \\
\hline 5 & 11 & Laundry cleaning services \\
\hline 6 & 15 & Printing \\
\hline 7 & 15 & Computer hardware \\
\hline 8 & 30 & Cleaning and pest control \\
\hline 9 & 11 & Marketing solutions \\
\hline 10 & 5 & Cleaning products \\
\hline 11 & 8 & Computer consumables \\
\hline 12 & 14 & Metal and water treatment products \\
\hline
\end{tabular}

The themes emergent from literature were used as point of departure to guide the thematic analysis. Eight themes pertaining to strategy formulation practices in SME's emerged. These will now be expounded upon. Excerpts from interviews have been included to support the findings. In the interest of brevity, these have been limited.

\section{Theme 1: The need for "strategy" in SMEs}

Interviews revealed that the majority of SME owner/managers (nine of the owner/managers in total) expressed that a definite need exists in SME's for prudent and focussed strategic management. A minority sentiment (from three research participants) was also expressed that did not support for the need for strategy in SMEs. 
As alluded to earlier, not all research participants received formal education or training in business management. This lead to instances where research participants had formed their own (often incorrect) opinions of what strategic management is. This was particularly evident from one research participant, who stated that a strategy was embarked upon on a monthly basis. Yet, when defining the activities associated to the monthly strategy, these were simply the compilation of standard financial monthly reports, such as a monthly balance sheet and a profit and loss statement.

The findings of this study do not support, or contradict, Sandberg et al's (2001:13) findings that half of all SMEs studied have no strategy as research participants were not questioned directly about having a strategy or not. Based on the verbatim statements it was evident that 75 percent of participants strongly support the need for a strategy.

The following excerpts support this theme:

SME 4: I think one of the disadvantages of the corporate is the amount of time spent on corporate strategy, although saying that, it is unavoidable. Small business ... I think we can avoid that and concentrate on the core of the business. I think small medium business cash flow is king. Um, I think management of the profitability of the business is critical; I think the other things just happen.

SME 6: I have a very good accounts package, so I do it [the small and medium enterprise strategy) from that.

SME 11: We don't run the business on a strategy; our success depends on us providing good aftersales service to our customers.

\section{Theme 2: Role-players in SME strategy formulation}

Further to the need for strategy in SMEs, findings also shed light on the role players within the respective SMEs involved with strategy formulation (or equivalent) activities. From the critical cases selected for the study, $50 \%$ of the research participants were single SME owners and $50 \%$ were co-owners of the SME.

In the case of SME's with single owners, the owner was the only role player involved in the formulation of strategy. This was the case with all but one of the single owner research participants. One respondent offered no response in this regard as this SME owner did not believe in running the business on the basis of a strategy.

SMEs with multiple owners, however, included multiple role-players in the formulation of their strategy. Three research participants reflected that only to the owners (or partners) of the SME were involved in strategy formulating activities. The other three co-owner participants mentioned that many role-players are involved in strategy formulation activities, including owners, senior and functional managers, and even strategic business partners, such as suppliers.

The following quotes from the interviews conducted with SME owner/managers bear witness to this theme:

SME 1: It's very important that the lower-level people are also part of that strategy sessions.

SME 4: No, it's really ... I would say that the strategic discussions are between the partners and the senior managers ... there are service managers involved in that and there are sales managers. So senior managers and ... and partners would be involved in that - and we do ... we do have those discussions. We discuss products, we discuss growth, discussing staff - how to retain staff, how to improve staff - and of course discussing how to do business.

SME 10: We have meetings every now and then to discuss it (strategy) 


\section{Theme 3: The nature of planning and forecasting in SMEs}

The majority of the research participants equated planning activities in financial terms. Activities such as sales forecasts, cash flow or revenue growth. Some research participants did, however, equate planning in terms of products and organisational structure.

One of the research participants reported that they only undertook planning and forecasting activities for the sake of their suppliers, who required quarterly forecasts for their planning. In fact, they preferred not to indulge in planning and forecasting activities, as the time spent on doing this could be better served generating income for the business.

Yet another research participant referred to their planning/forecasting activities as a 'Bahamas spreadsheet'; focussing on cash flow and ultimately how much money was in the bank. (The reference to the Bahamas referred to having enough cash flow to afford to retire in the Bahamas). Cash flow was also the focus of planning/forecasting activities of another research participant, as cash flow determined the ability to place new orders, which was ultimately the focus of all planning for their enterprise.

Although another SME owner/manager reflected that their enterprise did not spend much time on planning and forecasting, their use of planning and forecasting was put to a truly strategic use in that they consciously used this information to mplot courses of action for the SME. A contrasting response was provided by another SME, reporting this enterprise had no targets and didn't do any planning or budgeting (this enterprise had an annual turnover of R18 million in 2010). This enterprise preferred to go "day by day" and simply "play around with numbers".

Stonehouse and Pemberton (2002) indicated that most SMEs adopted a highly structured approach to planning and forecasting endeavours. However, this study seems to suggest the opposite, with research participants indicating either no planning/forecasting activities or a very haphazard and fragmented approach to planning and forecasting from a strategic management point of view. Although SME's do exhibit evidence of planning and forecasting, these are not necessarily utilised strategically. Indeed, only one of the critical cases selected for this study utilised planning and forecasting activities strategically.

The quotations below testify to the nature of planning/forecasting in SMEs:

SME5: Forecasting is not just done as part of the budget - we get input from each unit manager. The forecasts look at income; we do mini income statements, compare these to salaries and wages, repairs and maintenance.

SME 6: No we don't have targets. I do absolutely nothing - I don't do budgeting and I don't do targets. Our accountant does the budgets.

SME 10: Well, I think, obviously on the one side there is sort of financial planning, um, and then also strategy planning; but the strategy planning relates mainly to, um, what is the structure of the company, how it relates to particular resources. Because we are quite a small company, we think in terms of particular people - we say, well for the next year we can see where the market is going, there is a lot more of this type of work, so we need to maybe hire two more people ... So that's the one sort of planning and we do obviously do that through numbers, etcetera. The other planning is obviously financial, so we ... we use \{name removed\} to manage our finances etcetera. So we keep our focus on cash flow

\section{Theme 4: The SME planning timeframe}

The findings of the study suggest that none of the research participants partook in planning or forecasting activities beyond a 12 month period. Indeed 5 of the 12 SME's included in this study indulged in planning and forecasting activities for a maximum period of 12 months, but none of them extended these activities beyond 12 months. This supports the research 
findings of Gibson and Cassar (2002) as well as Yusuf and Saffu (2005), who both reported that SME planning activities have a maximum timeframe of one year.

Furthermore, planning and forecasting reliability varied amongst the research participants, with many research participants reporting that increased growth of the enterprise made it harder to forecast accurately and plan effectively. Other research participants reflected that it was difficult to determine a pattern in the current, volitile market circumstances in the wake of the 2008 Financial Crisis.

The following quotations from the interviews conducted bear witness to the planning timeframe in SMEs:

SME 3: ...so we, on a continuous basis have to plan and we ... we plan our workload three months ahead. And, and, and there, my production manager and my general manager play a major role in this.

SME 4: Um, that's usually quarterly or an annual basis.

SME 8: There is a year plan done at the beginning of the financial year -

SME 11: I do a month-to-month indication of deals, but no 12 month forecasts.

\section{Theme 5: Competitive intelligence for SMEs}

It was interesting to note that when discussing competitive intelligence gathered by the respective SME's included in this study, research participants reflected on the type of competitive intelligence they gathered, as well as the sources of the competitive intelligence. Only a few of the research participants discussed why gathering competitive intelligence was important to their SME

One research participant did not gather any competitive intelligence. All other research participants did and the type of competitive intellegence ranged from pricing, product or service offering to who the customers were and even what the value proposition was. Although most research participants interviewed actively sought competitive intelligence, none made reference to how the competitive intelligence was used to steer their SME into a particular direction. Two thirds of research participants (eight out of twelve) gathered competitive intelligence concerning pricing. Other research participants (five of the twelve research participants) reported gathering competitive intelligence pertaining to competitors' product and/or service offerings.

However, some research participants gathered competitive intelligence that has a more strategic application than information pertaining to operational issues, such as simple pricing data or service/product offering related information. Two of the selected SMEs reported gathering competitive intelligence on the overall approaches of their competitors. One research participant gathered competitive intelligence to determine the business potential of the competition, and another reported gathering competitive intelligence to establish the value propositions of competitors. This suggests that although this participant also wanted to know the prices of their competitor's offerings, they also wanted more in-depth knowledge of how competitors operated and where they fitted into the market - this instead of just a simple price benchmarking exercise, as indicated by most participants. Although this is evidence of competitor analysis, it is not, however, evidence of utilising competitive information to determine a future direction and strategic intent for the SME. The application of this competitor analysis still seems largely tactical, and not strategic.

Groom and David (2001) reported that SMEs are not focussed on gathering competitive intelligence, because of a lack of resources in most cases. The findings of this study thus seem to confirm the findings of Groom and David, with only four of the research participants reflecting that they actually gathered competitive intelligence beyond information which was freely available. 
Research done by Groom and David (2001) also revealed that SMEs typically gather competitive intelligence via their own employees and through interactions with their suppliers, customers and other industry contacts. This is reflected in the feedback from the research participants: 25 percent (three out of the 12 SMEs selected for this study) gathered competitive intelligence from their customers and 25 percent gathered competitive intelligence from their suppliers. This supports the findings of Abeson and Taku (2006), who identified suppliers as a main source of competitive intelligence. Competitive intelligence gathered through industry associations accounted for a further 25 percent of the instances reported.

In general, findings from this study support the view of Groom and David (2001) that SMEs are not overly occupied with gathering competitive intelligence and converting it into useful information for purposes of the development of a strategic plan.

The excerpts below indicate the sources of competitive intelligence revealed:

SME 3: I believe ... I believe for me to be competitive I have to know and understand my market. Not necessarily only the pricing structure, but also: the strategy, what it can offer, what the approach is, what the delivery details is. That is very important to the way I operate. I ... I understand very much how my opposition operate.

SME 9: Well, we spend a lot time looking at websites, 'cause obviously that's our key sort of industry. We are always evaluating what our competitor sites look like, plus the services that they offer: how they structure their pricing, what their value proposition is. So we always do look at that sort of thing. Um, but also we often go out to tenders and when we, let's say for instance a year-and-a-half ago when we did the \{name removed\} tender, and what we had to do there is say what is our leading value proposition, how we gonna position. Often when we are at a pitch, we would then look at our competitors to say who, potentially, is going to be involved in this and what angle should we take to present our company.

SME 12: Crucial, it's crucial. What we do is, you know, we do have pricing - pricing is important in our industry these days; in the past it wasn't as important. I know each and every product of my competitor. With all that information ... we use that information to structure synergies to obtain new business. We go out and do what we call a need analysis. We go determine, um: what their needs are; what services do they get from their supplier that they are happy with; what services would they like to have that they are not, uh, uh, that they don't receive from these people; downfalls of, um, the supplier um, surely we know their pricing. And then we look at: their turnover; the potential of the business.

\section{Theme 6: Strategy formulation in SMEs}

As mentioned, a lack of formal business management education and training amongst SME owner/managers resulted in research participants having their own view on what 'strategy' and 'strategic management' entailed. Many of these opinions did not necessarily correspond with scholarly literature on the subject. The majority of research participants spoke of strategy by referring to mission, vision, financial plans, business goals and objectives, business plans, long term goals, short and medium term objectives and annual projections. None of the research respondents, however, reflected on a process with respect to strategy formulation or business planning/forecasting. None of the research participants described how they went about formulating their strategies. Furthermore, no reference was made by any of the research participants to the use of any models or methodologies that exist in the discourse on strategic management for the purpose of strategy formulation.

The following quotations from the interviews conducted support this theme:

SME 1: When you start the business, you have to have your goals and objectives, okay - your shortterm and long-term goals. You need to strategise, okay: what are your short-term goals - it is to get the business off the ground, okay.

SME 2: It (the strategy) looks at a next year projection; it is evolving quite fast. 
SME 6: It's where I fit in the long-term and, uh, where should the business be going. I would say, going forward, one of the visions of the business would be growing annuity revenue.

SME 9: I find that the partners and myself essentially run the business very informally. We get together, I would say, every four/five months and then we evaluate our business - but not necessarily our positioning, but more in terms of our growth and profitability.

\section{Theme 7: Formalisation of strategies within SMEs}

For the purposes of this discussion, a distinction is made between strategic direction (evident in terms of a vision and mission for the SME) and a strategic plan (embodied in long term goals and objectives).

Three of the SMEs selected of this study had documented strategic direction, and two SMEs had documented strategic plans. Only one SME was in possession of a documented strategic direction and strategic plan. This SMEs' strategy was prepared annually and was aligned to that of the holding company's overall strategy. Some SMEs did possess strategic plans and/or strategic direction, but did not have it documented. In this regard, three SME owner/managers revealed that an undocumented strategic direction existed in their SME, and three SMEs had undocumented strategic plans. Of these, undocumented elements, one SME owner/manager reflected having both an undocumented strategic direction and strategic plan.

A number of SMEs reflected not having elements of strategy in place at all. Three SMEs did not possess a strategic direction and four SMEs had no strategic plan. One SME had neither a strategic plan nor strategic direction. It must be noted, however, that this SME owner/manager did specify that there were goals and objectives in place, but did not want to equate this to a formal strategy. Table 4 provides a summary of these findings

Table 4: Formalisation of strategy

\begin{tabular}{|l|l|l|l|}
\hline & $\begin{array}{l}\text { Strategic direction } \\
\text { only }\end{array}$ & $\begin{array}{l}\text { Strategic plan } \\
\text { only }\end{array}$ & $\begin{array}{l}\text { Both strategic direction } \\
\text { and -plan }\end{array}$ \\
\hline Existing and documented & 3 & 2 & 1 \\
\hline $\begin{array}{l}\text { Existing but } \\
\text { undocumented }\end{array}$ & 3 & 3 & 1 \\
\hline Non-existent & 3 & 4 & 1 \\
\hline
\end{tabular}

Frese et al (2000) discern between process strategy formulation (focussing on the "how strategy is formulated') and content strategy formulation (focussing on the 'what is formulated), but concludes that both are vital components of formulating a sound, implementable strategy. The findings of this study reveal that content strategy formulation is dominant amongst the SME's selected for this study, with the exception of one SME. In other words, planning efforts that do exist amongst these SME's focus squarely on a particular outcome the owner/co-owners want to achieve. Thus (with the exception of one SME) no evidence exists of formalised strategic planning and strategy formulation, as purported by contemporary strategic management literature.

The following excerpts from the interviews reflect the formalisation of strategy within SME's:

SME 1: We haven't really documented a strategy.

SME 2: We have a documented strategy and the financial projections. The thing is, we try to have values as well; so we don't really have a mission or vision.

SME 3: All in my head (the strategy, vision and mission). I share that with my general manager, I share that with my production manager and ... and also share that with certain role players in my customer base.

SME 7: Our mission is to be the printer supplier of choice for any of our customers. Um, and our core values are not just values: we live by them. They are not staff: we are family. 


\section{Theme 8: The link between strategy and SME performance}

Seven research participants) provided responses in respect of their view on the link between strategy and the performance of the SME. However, responses tended to be idealistic, almost creating the impression that research participants were trying to skirt the issue, or did not have a succinct opinion on the matter. Those research subjects that did respond to this issue felt that strategy can contribute to the success of an SME, but did not reflect whether that was the case for the SME they were (co)owner of. The excerpts below bear witness to this finding:

SME 1: I believe if you strategise, strategy should be flexible, adaptable to the environment. If you don't have a flexible strategy, it could determine your future growth: it could be your downfall.

SME 2: If you don't meet your projections, you go and evaluate why you have not met your projections and then correct that: it forces you to evaluate where you are.

SME 5: There are currently no linkages to strategy and individual performance, but we want to change that.

SME 9: Look, at this stage, we find we are very operational and whether the competitor is doing this or that doesn't really influence us. We do find we spend less time looking at the environment around us.

\section{MAIN CONCLUSIONS RESULTANT FROM THE STUDY}

From the findings and resultant discussion, the following points can be concluded form the study as far as strategy formulation in SME's is concerned:

- A definite need exists amongst SME owner/managers for focussed and succinct strategic management, although not all research participants are aware of all the intricacies of strategic management.

- Strategic planning endeavours are almost exclusively the domain of SME owners. Seemingly, those SMEs that are of larger scope tend to be more inclusive, but in general it is not an all-inclusive, participative approach as encountered in corporate firms.

- Strategic planning endeavours centre mainly around financial matters such as budgets, financial forecasts and cash-flow, underpinning the notion that SME owner/managers are not aware of the finer points of strategic planning.

- Planning timeframes do not exceed 12 months. This is indicative of the fact that SMEs focus more on operational efficiencies and functional tactics than on long tem plans. Also, the adaptive nature of SMEs require them to adopt shorter timeframes.

- Although all SMEs investigated do gather competitive intelligence as input for future decision making, this intelligence is mostly freely available information and not ac

- tually useful from a 'classical' strategic point of view. It is not useful for determining direction, it is more useful from an operational point of view.

- Not all SMEs have documented strategies. At best, SME's have embarked on strategic endeavours but it 'lives' in the mind of the SME (co)owner. Some SMEs, however, do not have any strategy at all.

- SME owner/managers interviewed feel that strategy can contribute to the success of their enterprises, but struggle to establish whether strategy can contribute to the success of their respective SMEs.

From the points above, it is evident that strategy formulation within SMEs differs from what is purported in contemporary strategic management literature. Therefore, strategy means something different, focusses on something different and unfolds differently in an SME than it does in a corporate setting. Strategy, therefore, in an SME setting should be approached and studied differently than strategic management in a corporate setting. It would seem as though strategic endeavours cannot be applied the same in an SME environment than in the corporate setting. 


\section{RECOMMENDATIONS, MANAGERIAL IMPLICATIONS AND AVENUES FOR FUTURE RESEARCH}

Support in favour of the need for sound strategic management practice in SMEs is evident in the literature of this study. However, in practice no strong evidence for the existence of strategy formulation, or any other tasks associated with long term planning, in the 'classic' sense of the term, could be found. SMEs realise the value of 'formal' strategies, yet these do not exist mainly due to an overemphasis on operational requirements and day-to-day survival. The implication is thus that a need exists to assist small and medium enterprises in the strategy formulation process. However, it must be stressed that conventional methodologies toward strategy formulation - and the management of strategy in general might not be applicable to SMEs. Strategic management literature has a definite application in the corporate milieu, and it is from this milieu that it was developed. However, SMEs are often managed by an entrepreneur/owner/manager and even in instances where a management team exists, the business owner is the guiding force. Thus many strategic activities seem to be implicit to the entrepreneur/owner/manager and this can be crucial to our understanding of not only strategy in a SME, but of strategy formulation in general.

None of the research participants did formal forecasting or planning beyond 12 months in advance. Thus SMEs seemingly do not attend to the long term future of their enterprises. This can have many subsequent implications that impact their environment and participants in that environment such as their suppliers and customers, or even at a macro level such as financial institution that may be required to provide financing without longer term business thinking. However, although no formal forecasting or strategic efforts beyond 12 months were evident, this does not necessarily imply that no strategic thinking took place or that no hypothetical strategic discussions took place between members of a management team. Although no evidence of the latter was forthcoming, it would be reasonable to assume that such thought processes or discussions do take place. Again, this leads one to conclude that although it might not be considered in the conventional vein, strategic planning activities do take place in SMEs, but in a different guise to what conventional literature purports.

The extent to which the research participants gathered competitive intelligence was evaluated in the research. Most research participants gathered competitive information in respect of the pricing of their competitors. The most common sources of this competitive information were from their suppliers and customers. This implies that the focus of their competitive intelligence is confined and does not look toward the overall strategies of their competition. Small and medium enterprises operate in very competitive environments. If they were able to determine the strategies of their competitors, they may be able to stay one step ahead of them. On the other hand, such limited competitive intelligence is incongruent with the longevity of some of the enterprises included in this research. It can also be argued that intuition and "gut-feel" do play a role in business success, and this seems to be an overlooked area of strategic management research as well as SME research.

It was disappointing to discover that none of the research participants had engaged formal strategy formation processes and that there was no evidence of documented strategies. The research did not attempt to explore the definition of strategy according to the research participants yet irrespective of their individual definition of strategy, there was no formality in respect thereof. The implication of this conclusion is similar to the implication identified in respect of forecasting and planning in respect of the broader view not being taken by the research participants in respect of their SMEs. 


\section{BENEFITS AND IMPORTANCE OF THE STUDY}

The formation of strategy is viewed by SME owner/managers as being potentially critical to the success of the SME If it is not done adequately. Improving strategy formulation (or equivalent) practices for SMEs could have an impact of the longevity of newly stated SMEs. This is critical, as the success rate of SMEs has a profound impact on the South African economy: as SMEs contribute in the area of $60 \%$ to the GDP of South Africa.

The research participants were not selected based on previous experience relating to strategy formulation. The research did not intend to understand or document the actual strategies of the SME research participants, nor their individual definitions of strategy, but focused on how the SME research participants go about formulating their strategies. As such, conventional strategic management practices were seen to be sorely lacking within the SMEs studied. However, this does not, as already highlighted, mean that strategy is not considered in SMEs, but rather that it is approached and considered differently. This paper attempts to highlight that strategic endeavours within SMEs should perhaps be evaluated according to criteria unique to SMEs.

\section{LIMITATIONS OF THE STUDY}

A limitation of the research was the likelihood of managers of SMEs revealing the detail of their strategy formation practices - particularly if these are not part of a formal process. Proper strategic planning gives an organisation a competitive edge; if it is perceived that the research questions may compromise this competitive edge, it may reduce the opportunity of partaking in the research. The research was limited to 12 research participants. The research did not consider the outcomes of their planning strategies i.e. the impact that the strategies they employ have on their enterprise. Thus, no measurement of their strategy success or failure was made. The research was limited to SMEs operating in Gauteng. This was done in consideration of access, cost and time limitations in respect of travel.

\section{CONCLUDING REMARKS}

The application of strategic management principles within the SME domain is an interesting one. There is a sentiment that management principles are generic and therefore SME research has no justification as a domain within the broader field of management. This research has shown that (at least for the discipline of Strategic Management) this sentiment is ill founded. It would appear as though the conventional, Porterean thinking behind strategy and long-term planning activities are not present at SMEs. Yet, notwithstanding this, success of many SME's is still secured. The only logical deduction would thus be that we should break free from conventional thinking on strategy within SME's and focus more attention on finding out why SMEs can still be successful despite this apparent lack of formalised attention to strategy.

\section{REFERENCES}

Abeson, F. \& Taku, M.A. (2006). Knowledge Source and Small Business Competitiveness. Competition Forum, 4(2):464-469. Available from: EBSCOHost: CINAHL: http://search.global.epnet.com/ (Accessed 25 August 2008).

Babbie, E. and Mouton, J. (2004). The practice of social research. Cape Town: Oxford University Press

Bennett, R.J. \& Robson, P.J.A. (2003). Changing Use of External Business Advice and Government Supports by SMEs in the 1990s. Regional Studies, 37(8):795-811. 
Available from: EBSCOHost: CINAHL: http://search.global.epnet.com/ (Accessed 27 February 2009).

Berman, J.A., Gordon, D.D. \& Sussman, G. (1997). A study to determine the benefits small business firms derive from sophisticated planning versus less sophisticated types of planning. Journal of Business and Economic Studies, 3(3):1-11. Available from: EBSCOHost: CINAHL: http://search.global.epnet.com/ (Accessed 10 July 2008).

Braun, V \& Clarke, V. (2006). Using thematic analysis in psychology. Qualitative Research in Psychology, (3)77-101. Available from EBSCOHost: CINAHL: http://search.global.epnet.com/ (Accessed 19 June 2010).

Dibrell, C., Down, J. \& Bull, L. (2007). Dynamic Strategic Planning: Achieving Strategic Flexibility Through Formalization. Journal of Business Management, 13(1):21-35. Available from: EBSCOHost: CINAHL: http://search.global.epnet.com/ (Accessed 12 May 2008).

Dyer, L.M. \& Ross, C.A. (2008). Seeking advice in a dynamic and complex business environment: impact on the success of small firms. Journal of Developmental Entrepreneurship, 13(2):133-149. Available from: EBSCOHost: CINAHL: http://search.global.epnet.com/ (Accessed 27 February 2009).

Feurer, R. \& Chaharbaghi, K. (1997). Strategy development: past, present and future. Training for Quality, 5(2):58-70. Available from: Available from: EBSCOHost: CINAHL: http://search.global.epnet.com/ (Accessed 22 May 2006).

Flick, U. (2006). An introduction to qualitative research. London: Sage Publication.

French, S.J., Kelly, S.J. \& Harrison, J.L. (2004). The role of strategic planning in the performance of small, professional service firms. A research note. The Journal of Management Development, 23(7/8):765-776. Available from: EBSCOHost: CINAHL: http://search.global.epnet.com/ (Accessed 10 July 2008).

Frese, M., Van Gelderen, M. \& Ombach, M. (2000). How to Plan as a Small Scale Business Owner: Psychological Process Characteristics of Action Strategies and Success. Journal of Small Business Management, 38(2):1-18. Available from: EBSCOHost: CINAHL: http://search.global.epnet.com/ (Accessed 12 May 2008).

Gibson, B. \& Cassar, G. (2002). Planning Behavior Variables in Small Firms. Journal of Small Business Management, 40(3):171-186. Available from: EBSCOHost: CINAHL: http://search.global.epnet.com/ (Accessed 10 July 2008).

Griggs, H.E. (2002). Strategic Planning System Characteristics and Organisational Effectiveness In Australian Small-Scale Firms. Irish Journal of Management, 23(1):2351. Available from: EBSCOHost: CINAHL: http://search.global.epnet.com/ (Accessed 10 July 2008).

Jackson, G. (n.d.) Corporate Finance and Strategy. Available from: http://back-2basics.co.za. (Accessed 6 March 2009).

Groom, J.R. \& David, F.R. (2001). Competitive Intelligence Activity Among Small Firms. S.A.M. Advanced Management Journal, 66(1):12-20. Available from: EBSCOHost: CINAHL: http://search.global.epnet.com/ (Accessed 12 May 2008). 
Keats, B.W \& Bracker J.S. 1998. Toward a Theory of Small Firm Performance: A Conceptual Model. American Journal of Small Business, 12(4):41-58. Available from: EBSCOHost: CINAHL: http://search.global.epnet.com/ (Accessed 12 May 2008).

Kraus, S., Harms, R. \& Schwarz, E.J. (2006). Strategic planning in smaller enterprises - new empirical findings. Management Research News, 29(6):334-344. Available from: EBSCOHost: CINAHL: http://search.global.epnet.com/ (Accessed 7 July 2008).

Lincoln, Y.S. \& Guba, E.G. (1985). Naturalistic Inquiry. Newbury Park: Sage.

Mintzberg, H., Ahlstrand, B. \& Lampel, J. (1998). Strategy safari. The complete guide through the wilds of strategic management. United States of America: Prentice Hall.

Meers, K.A. \& Robertson, C. (2007). Strategic Planning Practices in Profitable Small Firms in the United States. The Business Review, 7(1):302-307. Available from: EBSCOHost: CINAHL: http://search.global.epnet.com/ (Accessed 12 May 2008).

Miller, R.L. \& Brewer, J.D. (Editors). (2003). The A-Z of Social Research. A Dictionary of Key Social Science Research Concepts. London: Sage Publications.

Montgomery, C.A. (2008). Putting leadership back into strategy. Harvard Business Review, 54-60. Available from: EBSCOHost: CINAHL: http://search.global.epnet.com/ (Accessed 10 July 2008).

Mughan, T., Lloyd-Reason, L. \& Zimmerman, C. (2004). Management consulting and international business support for SMEs: need and obstacles. Education and Training Journal, 46(8/9):424-432. Available from: EBSCOHost: CINAHL: http://search.global.epnet.com/ (Accessed 25 August 2008).

Neuman, W.L. (2003). Social Research Methods: Qualitative and quantitative approaches. Boston: Allyn \& Bacon.

O'Regan, N. \& Ghobadian, A. (2004b). Leadership and Strategy: Making it Happen. Journal of General Management, 29(3):76-92. Available from: EBSCOHost: CINAHL: http://search.global.epnet.com/ (Accessed 6 March 2009).

Perry, S.C. (2001). The Relationship between Written Business Plans and the Failure of Small Businesses in the U.S. Journal of Small Business Management, 39(3):201-208. Available from: EBSCOHost: CINAHL: http://search.global.epnet.com/ (Accessed 10 July 2008).

Pun, K.F. (2004). A conceptual synergy model of strategy formulation for manufacturing. International Journal of Operations \& Production Management, 24(9/10):903-928. Available from: EBSCOHost: CINAHL: http://search.global.epnet.com/ (Accessed 10 July 2008).

Sandberg, W.R., Robinson, R.B. \& Pearce, J.A. (2001). Why Small Businesses Need a Strategic Plan. Business and Economic Review, 48(1):12-15. Available from: EBSCOHost: CINAHL: http://search.global.epnet.com/ (Accessed 26 August 2008).

Stonehouse, G. \& Pemberton, J. (2002). Strategic planning in SMEs - some empirical findings. Management Decisions, 40(9):853-861. Available from EBSCOHost: CINAHL: http://search.global.epnet.com/ (Accessed 10 July 2008). 
Strauss, A., \& Corbin, J. (1998). Basics of qualitative research: Techniques and procedures for developing Grounded theory. London: Sage Publications.

Terre Blanche, M., Durrheim, K. and Painter, D. (2006). Research in Practice: Applied Methods for the Social Sciences. Cape Town: UCT Press.

Thompson, A.A., Strickland, A.J. \& Gamble, J.E. (2005) Crafting and Executing Strategy: The Quest for Competitive Advantage. New York: McGraw-Hill.

Van Gelderen, M., Frese, M. \& Thurik, R. (2000). Strategies, uncertainty and performance of small business startups. Small Business Economics 15(3):165-184. Available from: EBSCOHost: CINAHL: http://search.global.epnet.com/ (Accessed 10 July 2008).

Walliman, N. (2006). Social research method. London: Sage Publications.

Wijewardena, H., De Zoysa, A., Fonseka, T. \& Perera, B. (2004). The Impact of Planning and Control Sophistication on Performance of Small and Medium-Sized Enterprises: Evidence from Sri Lanka. Journal of Small Business Management 42(2):209-217. Available from: EBSCOHost: CINAHL: http://search.global.epnet.com/ (Accessed 10 July 2008).

Yusuf, A. \& Saffu, K. (2005). Planning and Performance of Small and Medium Enterprise Operators in a Country of Transition. Journal of Small Business Management, 43(4):480-497. Available from: EBSCOHost: CINAHL: http://search.global.epnet.com/ (Accessed 10 July 2008). 